\title{
Nitrile rubber and carboxylated nitrile rubber resistance to soybean biodiesel
}

\author{
Felipe Nunes Linhares ${ }^{1 *}$, Cléverson Fernandes Senra Gabriel'1, Ana Maria Furtado de Sousa ${ }^{1}$, \\ Marcia Christina Amorim Moreira Leite ${ }^{1}$ and Cristina Russi Guimarães Furtado ${ }^{1}$
}

\author{
${ }^{1}$ Laboratório de Processamento de Polímeros, Instituto de Química, \\ Universidade do Estado do Rio de Janeiro - UERJ, Rio de Janeiro, RJ, Brazil \\ *felipe.n.linhares@gmail.com
}

\begin{abstract}
Biodiesel has been considered a suitable substitute for petroleum diesel, but their chemical composition differs greatly. For this reason, biodiesel interacts differently than petroleum diesel with various materials, including rubbers. Therefore, the resistance of some elastomers should be thoroughly evaluated, specifically those which are commonly used in automotive industry. Nitrile rubber (NBR) is widely used to produce vehicular parts that are constantly in contact with fuels. This paper aimed to assess the resistance of carboxylated nitrile rubber (XNBR) with $28 \%$ of acrylonitrile content to soybean biodiesel in comparison with non-carboxylated nitrile rubber samples, with high and medium acrylonitrile content (33 and 45\%). NBR with medium acrylonitrile content showed little resistance to biodiesel. However, carboxylated nitrile rubber even with low acrylonitrile content had similar performance to NBR with high acrylonitrile content.
\end{abstract}

Keywords: nitrile rubber, crosslink density, biodiesel, mechanical properties.

\section{Introduction}

Nitrile rubber (NBR) represents a rubber for special purposes and it highly resistant to mineral oils and non-polar solvents, due to the presence of nitrile groups in its structure. One of its the main applications is in the automotive industry, in parts that requires constant contact with fuels.

The degradation of nitrile rubber can occur via different ways, including changes in the crosslink network and reactions with free carbon double bonds ${ }^{[1-4]}$. Carbon black can also accelerate the thermal oxidation process of NBR compounds ${ }^{[1-5]}$.

Some studies ${ }^{[4,6-17]}$ have tested the compatibility of many elastomers to biodiesel, including nitrile rubber (NBR), whose degradation process is often assessed observing changes in the mechanical properties after static and/or dynamic immersion in different types of media at different temperatures.

Biodiesel is a liquid bio-fuel considered to be an environmentally friendly source of energy, and a feasible alternative to petrol-diesel. It is chemically defined as a mixture of mono-alkyl esters obtained from vegetable oils or animal fat.

There are many vegetable sources for biodiesel production, such as soybean oil, palm oil, and rapeseed oil, among others. Some differences in physico-chemical properties are observed depending on the feedstock used for the biodiesel production ${ }^{[18,19]}$.

Petroleum diesel and biodiesel interact differently with various materials, as both are chemically different. For this reason, the properties of biodiesel should be further studied. To date, biodiesel compatibility with materials that are used widely in diesel engines has not been fully assured.
Usually nitrile rubber presents low resistance to biodiesel from different sources. Trakarnpruk and Porntangjitlikit ${ }^{[6]}$, and Dubovský et al. ${ }^{[13]}$ suggested that the deterioration in mechanical properties were due to the plasticization effect of biodiesel. However, the use of a biodiesel/diesel 10\% blend (B10) should not be of concern ${ }^{[6]}$.

Haseeb et al. ${ }^{[7,8]}$ inferred that the degradation process occurs due to reactions with the crosslink network, and with the free double bonds in the polymer chains. Linhares et al. ${ }^{[10]}$ concluded that an increase in the acrylonitrile content increases the nitrile rubber resistance to biodiesel. Akhlaghi et al..$^{[4,14]}$ showed that the biodiesel attacks the filler-elastomer interfaces, which affect the mechanical properties; in addition, biodiesel would decrease the crosslink network of elastomer compounds. Akhlaghi et al. ${ }^{[14]}$ also suggested that a prolonged exposure to biodiesel can promote the hydrolisation of nitrile groups of NBR by $\mathrm{Zn}^{+2}$ cations. Moreover, the chemical differences of biodiesel obtained from different sources can affect the biodiesel solvent power, and, hence, its degradation power ${ }^{[15]}$.

However, most of the authors did not specify the acrylonitrile content in the nitrile rubber samples nor which formulations were used during the tests, impeding a thorough comparison of the results.

Considering that biodiesel is an actual fuel option, and nitrile rubber is largely used for automotive parts production, the need to study the interaction between biodiesel and elastomers is urgent.

This paper aimed to evaluate the resistance of different nitrile rubber samples to soybean biodiesel. The novelty of this paper lies on the assessment of carboxylated nitrile rubber performance after immersion in soybean biodiesel, 
and of the relation of different types of crosslink network with elastomer resistance to soybean biodiesel.

\section{Materials and Methods}

\subsection{Compounding}

Nitrile rubber samples with different acrylonitrile content (33 and $45 \%$ ) and carboxylated nitrile rubber (with $28 \%$ of acrylonitrile content) were used. The rubber samples were generously given by Nitriflex S/A Indústria e Comércio. The compositions were prepared in a roll mill, at $50{ }^{\circ} \mathrm{C} \pm 5^{\circ} \mathrm{C}$ $(323 \mathrm{~K} \pm 5 \mathrm{~K})$, as per ASTM D3187, using the formulation presented in Table 1. The carbon black sample was given by Cabot do Brasil Indústria e Comércio S.A..

For identification purposes the compositions prepared were labelled according to the elastomer used in the formulation: $N B R 33$ for the composition prepared with nitrile rubber with $33 \%$ of acrylonitrile; $N B R 45$ for the composition with nitrile rubber with $45 \%$ of acrylonitrile; and $X N B R$ for the compositions prepared with the carboxylated nitrile rubber with $28 \%$ of acrylonitrile content. Further information on the nitrile rubber samples is given in Table 2 .

A small sample of each composition was analysed on a Tech Pro MDPt moving die rheometer (MDR), for one hour, at $160^{\circ} \mathrm{C}(433 \mathrm{~K})$ to establish the optimum cure time $\left(\mathrm{t}_{90}\right)$ of each composition. The compositions were vulcanised in a hydraulic press using their respective $t_{90}$ to obtain testing specimens for the mechanical tests.

\subsection{Crosslink density}

Crosslink density of the samples was calculated by equilibrium swelling with acetone, using the Flory-Rehner equation $^{[2,21]}$ (Equation 1), at room temperature.

Table 1. Formulation of the NBR compositions, as per ASTM D3187, in phr ${ }^{\mathrm{a}}$.

\begin{tabular}{cc}
\hline Component & Amount in $_{\text {phr }} \mathbf{a}^{\mathbf{a}}$ \\
\hline Nitrile rubber & 100 \\
Zinc oxide & 3 \\
Stearic Acid & 1 \\
Sulphur & 1.5 \\
TBBS $^{\mathrm{b}}$ & 0.7 \\
Carbon black (SP6630) & 40 \\
\hline
\end{tabular}

${ }^{a}$ parts per hundred parts of rubber; ${ }^{b} \mathrm{~N}$-tert-butyl-2-benzothiazyl sulphenamide.

$$
\eta=\frac{-\left[\ln \left(1-v_{r}\right)+v_{r}+\chi\left(v_{r}^{2}\right)\right]}{\left[V_{0}\left(v_{r}^{\frac{1}{3}}-\frac{v_{r}}{r}\right)\right]}
$$

wherein $\eta$ is the crosslink density; $v_{R}$ is the volume fraction of rubber in equilibrium swollen vulcanizate sample; $V_{0}$ is the molar volume of the solvent $\left(73.40 \mathrm{~mL} \cdot \mathrm{mol}^{-1}\right) ; \chi$ is the interaction parameter between the solvent and the elastomer.

The volume fraction of rubber in equilibrium swollen gel $\left(v_{R}\right)$ was calculated according to Equation 2. It is worth mentioning that the filler volume was subtracted of the rubber volume in the calculation.

$$
v_{r}=\frac{\frac{M_{1}-f_{f} M_{1}}{\rho_{c}}}{\frac{M_{1}-f_{f} M_{1}}{\rho_{c}}+\frac{M_{2}-M_{3}}{\rho_{s}}}
$$

wherein, $M_{l}$ is the initial sample mass; $f_{F}$ is the filler fraction volume; $\rho_{C}$ is the calculated composition density; $M_{2}$ is the swollen sample mass; $M_{3}$ is the deswollen sample mass; $\rho_{S}$ is the solvent density $\left(0.79 \mathrm{~g} \cdot \mathrm{mL}^{-1}\right)$.

The interaction parameter $(\chi)$ for each composition was calculated according to the Equation $3^{[22]}$.

$$
\chi=\beta_{1}+\left(\frac{V_{0}}{R T}\right)\left(\delta_{s}-\delta_{p}\right)^{2}
$$

wherein, $\beta_{1}$ is the lattice constant ${ }^{[22]}(0.34) ; R$ is the universal gas constant; $T$ is the temperature in Kelvin; $\delta_{S}$ is the solubility parameter of the solvent (9.9 for acetone ${ }^{[23]}$ ); $\delta_{P}$ is the solubility parameter of the polymer (varies for each rubber sample $\left.{ }^{[23]}\right)$.

The calculated interaction parameter $(\chi)$ for $N B R 33$ was 0.3507; for $N B R 45$ was 0.3474 ; and for $X N B R$ was 0.3640 .

The dried compositions density $\left(\rho_{c}\right)$ was calculated following the Arquimedes' principle, in which consider the mass of the sample in air, the apperent mass of the sample immersed in the solvent, and the density of the solvent. The apparent mass of the sample is measured using a proper apparatus, which measures the mass of the sample submerged in the solvent (acetone) held by a thread. The density was, then, calculated according to Equation 4.

$$
\rho_{c}=\frac{M_{1}}{\left(M_{1}-M_{4}\right)} x \rho_{s}
$$

wherein, $M_{4}$ is the apperent mass of the sample immersed in the solvent.

Table 2. Main properties of the nitrile rubber samples*.

\begin{tabular}{cccc}
\hline Property & $\begin{array}{c}\text { Nitrile rubber sample with } \\
\mathbf{3 3 \%} \text { of acrylonitirle }\end{array}$ & $\begin{array}{c}\text { Nitrile rubber sample with } \\
\text { 45\% of acrylonitirle }\end{array}$ & $\begin{array}{c}\text { Carboxylated nitrile } \\
\text { rubber sample with 28\% of } \\
\text { acrylonitirle }\end{array}$ \\
\hline $\begin{array}{c}\text { Bound acrylonitrile (\%)-ASTM } \\
\text { D3533 }\end{array}$ & 32 & 46.7 & 27.8 \\
Mooney viscosity & 45 & 55 & 45 \\
(MML1+4 @373K) - ASTM D1646 & 0.1 & 0.1 & 0.1 \\
Ash content (\%)-ASTM D5667 & 0 & & \\
\hline
\end{tabular}

* given by the supplier Nitriflex S/A Indústria e Comércio. 


\subsection{Immersion tests}

Pure soybean ethylic biodiesel, kindly donated by CENPES/Petrobras (Brazil), was used for the immersion tests. The biodiesel properties were within the Brazilian regulations, and its main components are ethyl esters derived from mono and poly-unsaturated acids ${ }^{[18,19]}$.

\subsection{Change in mass}

Small rectangular specimens were cut from the vulcanised sheets to assess the change in mass after immersion according to ASTM D471. The specimens were weighed, in air, in a balance with $0.1 \mathrm{mg}$ accuracy. The immersed samples had their surfaces dried with filter paper before they were weighed. The results were the average change in mass from the tested specimens. The immersion was conducted for $22 \mathrm{~h}$ at $100{ }^{\circ} \mathrm{C}(373 \mathrm{~K})$ in an oven with forced air circulation.

\subsection{Mechanical tests}

Stress-strain tests were performed on a testing machine EMIC, model DL2000, as per ASTM D412, using Die $\mathrm{C}$ dumbbell specimens, i.e., $115 \mathrm{~mm}$ length, and bench mark distance of $25.4 \mathrm{~mm}$. The rate of grip separation was $500 \mathrm{~mm} / \mathrm{min}( \pm 50 \mathrm{~mm} / \mathrm{min})$. Tear strength tests were conducted on the same testing machine according to ASTM D624, using Type $\mathrm{C}$ test specimens, i.e., an unnicked test piece with a $90^{\circ}$ angle on one side, and $102 \mathrm{~mm}$ length. The rate of grip separation was also $500 \mathrm{~mm} / \mathrm{min}( \pm 50 \mathrm{~mm} / \mathrm{min})$. Hardness tests were performed on a durometer Shore A, from Parabor, following ASTM D2240, and the testing

\subsection{Scanning electron microscopy}

After the mechanical tests, the fracture surfaces of the immersed and the non-immersed samples were sputtered with a gold film and analysed by scanning electron microscopy (SEM), using $15 \mathrm{keV}$ electron beam acceleration voltage in a JSM 6510LV microscope from JEOL.

\section{Results and Discussions}

\subsection{Change in mass}

Change in mass of the compositions after the immersion in the bio-fuel is shown in Figure 1. NBR33, with medium acrylonitrile content $(33 \%)$, absorbed the fuel in the highest extent, increasing in over than $50 \%$ its mass. On the other hand, $X N B R$, with only $28 \%$ of acrylonitrile content, swelled around $30 \%$, and $N B R 45$, as expected, absorbed the oil in much lower extension, increasing in less than $15 \%$ of its mass.

Differently from these results, Akhlaghi et al. ${ }^{[14]}$ found an increase in mass between 10 to $15 \%$ for nitrile rubber compositions with $34 \%$. The difference in the results can be assigned to the different biodiesel source used (rapeseed in their study and soybean in this study), and also to the lower temperature employed in the cited reference. Nonetheless, the tendency that increasing the acrylonitrile content, decreases the biodiesel uptake was similar in both studies.

The bio-fuel swelling by the NBR33 sample is usually attributed to the "like dissolves like" principle ${ }^{[4]}$ since biodiesel presents some polarity due to its ester nature. The closeness

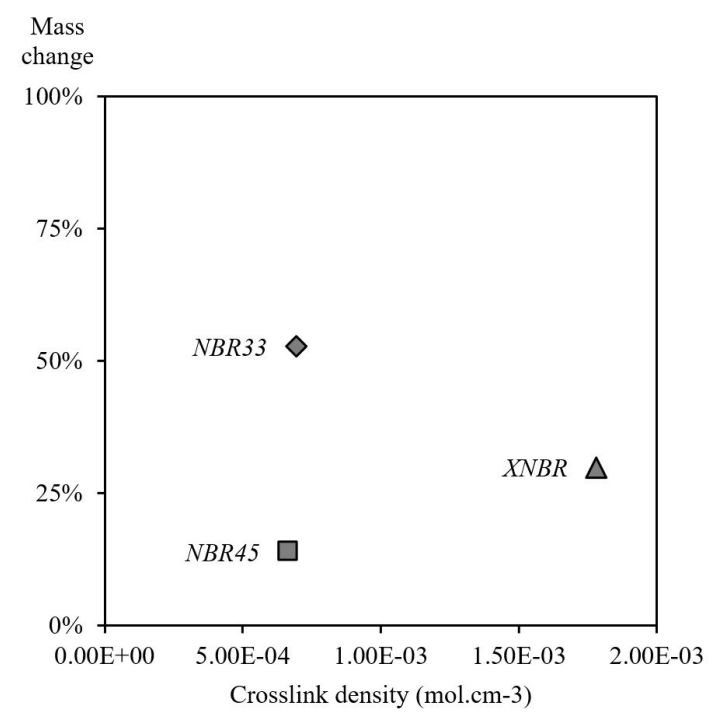

Figure 1. Change in mass after $22 \mathrm{~h}$ of immersion in soybean biodiesel as function of crosslink density of the nitrile rubber compositions.

of polarity between the fluid and the elastomer eases the diffusion of the fuel into the polymer.

Figure 1 also matches the crosslink densities of each composition with the oil mass uptake after $22 \mathrm{~h}$. Some authors ${ }^{[7,8]}$ proposed that an increase in acrylonitrile content would increase the crosslink density, which would lessen the bio-fuel swelling. Our results disagreed with these propositions. Crosslink density presented no relation with the compositions' acrylonitrile content, as NBR 45 and NBR33 had similar crosslink density. $X N B R$ can form additional non-sulphur crosslink bonds through the carboxyl groups ${ }^{[24]}$, which explains the highest crosslink density achieved. These crosslinks are formed by the interaction between carboxyl groups and zinc ${ }^{[24]}$.

In addition, the biodiesel swelling was also not related to the crosslink density of the compositions. Carboxylated nitrile rubber $(X N B R)$ absorbed less oil than $N B R 33$, but swelled more oil than NBR45.

We could observe that the crosslink density of the compositions solely does not rule the degree of biodiesel swelling. Based on these results, differences in biodiesel absorption should be assigned to a contribution of both the acrylonitrile content and the type of crosslink.

\subsection{Mechanical tests}

The mechanical test results from the different NBR compositions after the immersion in pure soybean biodiesel were presented as the relative change after the immersion in comparison with those non-immersed ones, and are depicted in Figures 2 and 3.

NBR33 presented very low resistance to soybean biodiesel, given that the losses of the mechanical properties were $66 \%$ on average. $N B R 45$, however, experienced less significant losses, $38 \%$ on average, after immersion in biodiesel. Previous tests already showed better resistance 

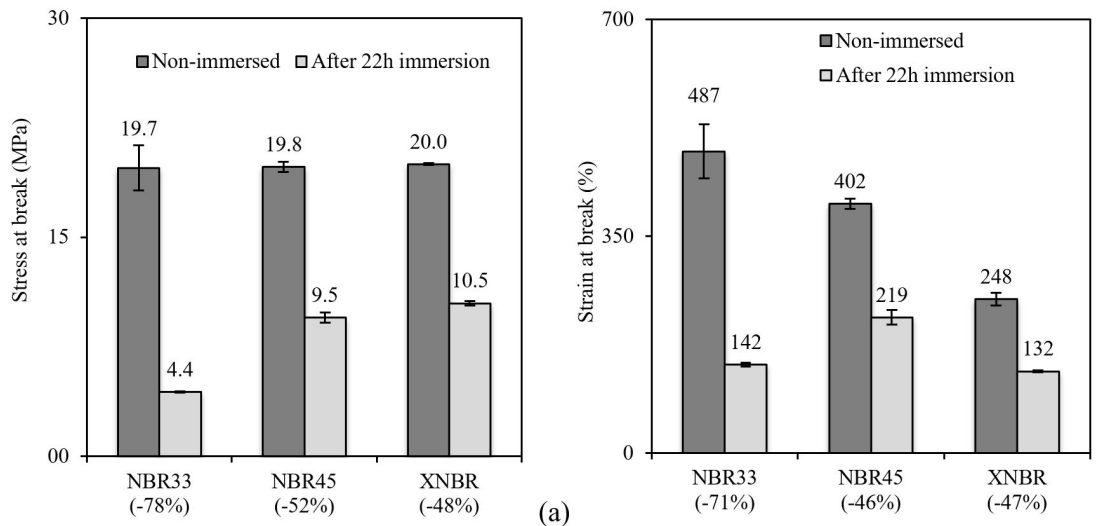

(b)

Figure 2. (a) Stress at break, and (b) strain at break of nitrile rubber compositions: non-immersed, and after immersion in soybean biodiesel for $22 \mathrm{~h}$ at $100{ }^{\circ} \mathrm{C}$. Between brackets the percentage of loss of the properties.
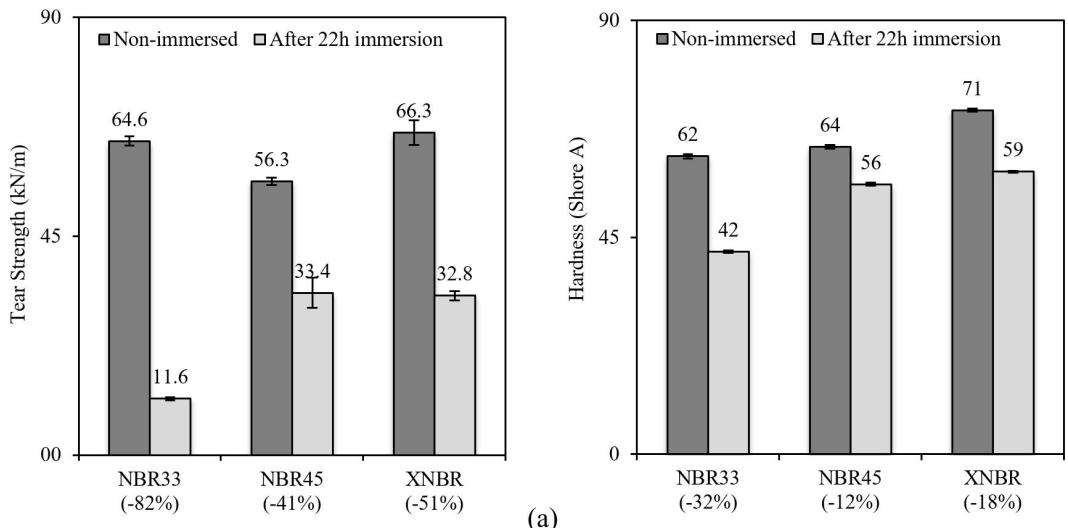

(b)

Figure 3. (a) Tear strength, and (b) hardness of nitrile rubber compositions: non-immersed, and after immersion in soybean biodiesel for $22 \mathrm{~h}$ at $100{ }^{\circ} \mathrm{C}$. Between brackets the percentage of loss of the properties.

to biodiesel for samples with higher acrylonitrile content ${ }^{[10]}$, in spite of they had been conducted at different conditions.

Despite having low acrylonitrile content (28\%), the carboxylated nitrile rubber composition presented an average loss of $41 \%$, which was close to those observed for high acrylonitrile content composition (NBR45). Moreover, $X N B R$ had a better resistance to biodiesel than medium acrylonitrile content composition (NBR33). This suggests that the resistance of nitrile rubber samples are not merely assigned to the acrylonitrile content of the samples.

The losses of stress at break after immersion were matched with the samples' crosslink densities (Figure 4a) and with the mass change of each composition (Figure 4b).

Once again, we could observe that crosslink density solely does not rule rubber resistance to biodiesel (Figure 4a). NBR33 and NBR45, which have similar crosslink density, presented remarkably different mechanical resistance to biodiesel, which, for these compositions, may be assigned to the difference in the acrylonitrile content. On the other hand, $X N B R$, with the highest crosslink density, had similar loss to NBR45. As already mentioned, carboxylated samples can form different kinds of crosslink bonds, because of the presence of carboxyl groups.
This additional type of crosslink improved the rubber resistance to biodiesel, despite the fact that $X N B R$ has the lowest acrylonitrile content among the compositions. The crosslink networks of the compositions NBR33 and $N B R 45$ were mostly composed by polysulfide crosslinks, which are less resistant to thermal and chemical oxidation.

We could infer that the presence of different types of crosslink network compensates the lower acrylonitrile content.

Comparing the stress at break losses with the change in mass after $22 \mathrm{~h}$ (Figure $4 \mathrm{~b}$ ), we could highlight that $X N B R$ has a superior resistance to biodiesel, since these samples had similar mechanical performance to NBR45 after immersion in biodiesel, despite of having had a larger oil uptake.

The mechanical losses observed could be attributed to the reduction of the polymer chains entanglement ${ }^{[6]}$, oxidation of free double bonds, and reduction of polymer-filler interaction $^{[4,7,14,25]}$, which were provoked by the diffusion of the biodiesel into the samples. The detrimental effects of the oil also come from its low oxidative stability, which is due to the high presence of unsaturated components ${ }^{[4,18,26]}$. The oxidation of biodiesel results in the formation of carboxylic acids as well as water ${ }^{[4]}$, which can detrimentally react with the rubber network. 


\subsection{Scanning Electron Microscopy (SEM)}

SEM analyses were also conducted to give further support to the observations already drawn. The fracture surfaces from all tensile tests specimens' compositions are shown in Figure 5.

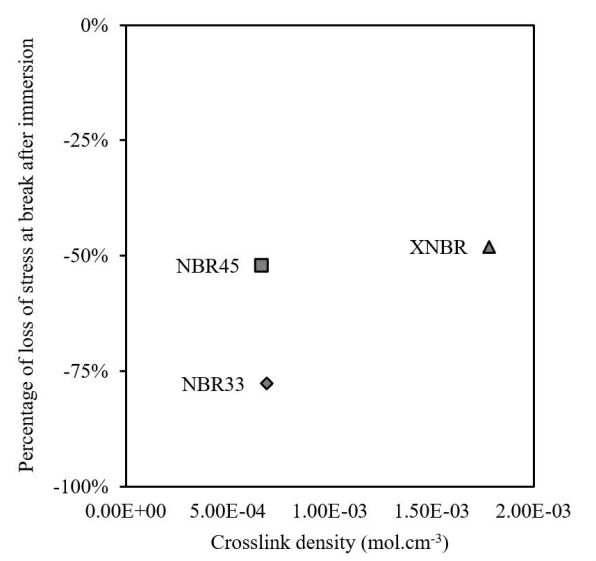

(a)
NBR33 showed a highly deteriorated surface after the immersion compared to the non-immersed specimen. Many clusters on the surface of the immersed samples could be observed. The modified surface suggests a strong, yet destructive, affinity between the biodiesel and the elastomer.

Figure 4. Percentage of loss of stress at break after $22 \mathrm{~h}$ of immersion in soybean biodiesel of the nitrile rubber compositions as function of: (a) crosslink density (a); and (b) mass uptake.

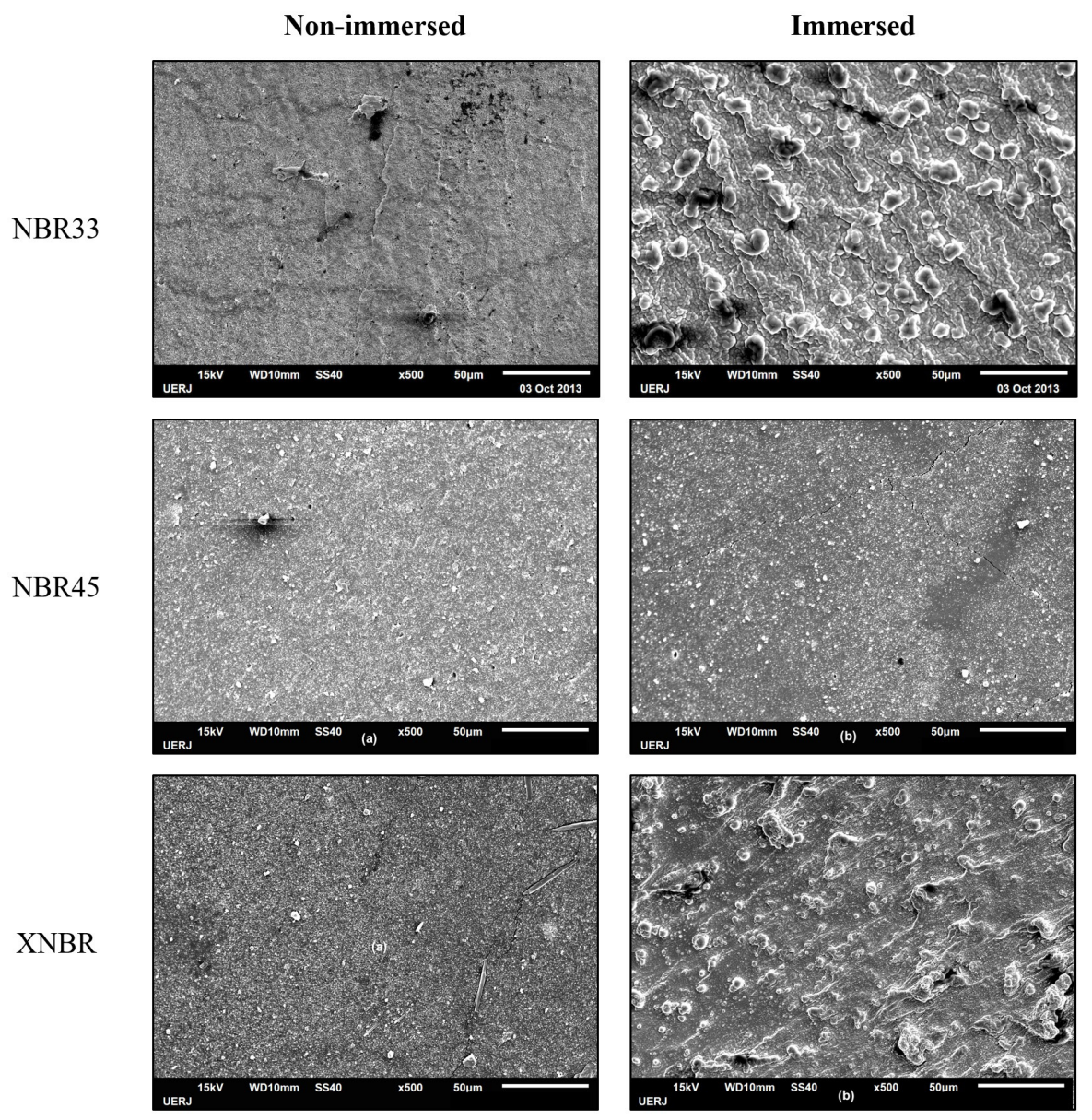

Figure 5. SEM Photomicrographs of fracture surfaces from the nitrile rubber samples. Non-immersed samples, and after immersion in soybean biodiesel for $22 \mathrm{~h}$ at $100^{\circ} \mathrm{C}$. 
On the other hand, the surface of NBR45 sample was not much attacked after the immersion, as no modification was observed, which suggests weak affinity between the fuel and the composition with high acrylonitrile content. This suggestion is corroborated by the low oil uptake by that composition. This behaviour is beneficial considering the use of this type of nitrile rubber in some applications.

The photomicrographs from $X N B R$ fracture surface only presented a few small clusters formed, indicating a moderate chemical interaction between the elastomer and the biodiesel. The different nature of the crosslink bonds might have contributed to lower detrimental interactions, despite the lower acrylonitrile content.

Furthermore, the SEM photomicrographs corroborates the results observed in Figure 1. It was observed that the compositions which absorbed more biodiesel presented a more modified fracture surface after immersion.

\section{Conclusions}

Based on the results from the mechanical tests and the SEM analyses, we could conclude the compositions NBR45 and XNBR presented similar mechanical performace after immersion in soybean biodiesel. Moreover, despite having lower acrylonitrile content (28\%), the carboxylated nitrile rubber exhibited a better performance after immersion in soybean biodiesel compared to the medium-acrylonitirle-content composition (NBR33). Furthermore, other conclusions could also be drawn from our results:

1) Increasing the acrylonitrile content of the elastomer improves the resistance of nitrile rubber samples to biodiesel;

2) Different crosslink systems also enhance the resistance to biodiesel, despite the acrylonitrile content;

3) The stress and strain losses were not directly affected by the amount of biodiesel absorbed by the compositions.

\section{Acknowledgements}

The authors acknowledge Nitriflex S/A Indústria e Comércio and Cabot do Brasil Indústria e Comércio S.A. for material supply; Centro de Pesquisa e Desenvolvimento Leopoldo Américo Miguez de Mello (CENPES/PETROBRAS) for the biodiesel supply; Fundação Carlos Chagas Filho de Amparo à Pesquisa do Estado do Rio de Janeiro (FAPERJ) for the financial support; Richard T. Herbert for English revision.

\section{References}

1. Zhao, J., Yang, R., Iervolino, R., \& Barbera, S. (2013). Changes of chemical structure and mechanical property levels during thermo-oxidative aging of NBR. Rubber Chemistry and Technology, 86(4), 591-603. http://dx.doi.org/10.5254/ RCT.13.87969.

2. Xiong, Y., Chen, G., Guo, S., \& Li, G. (2013). Lifetime prediction of NBR composite sheet in aviation kerosene by using nonlinear curve fitting of ATR-FTIR spectra. Journal of Industrial and Engineering Chemistry, 19(5), 1611-1616. http://dx.doi.org/10.1016/j.jiec.2013.01.031.

3. Datta, R. N., Huntink, N. M., Datta, S., \& Talma, A. G. (2007). Rubber vulcanizates degradation and stabilization. Rubber Chemistry and Technology, 80(3), 436-480. http://dx.doi. org/10.5254/1.3548174.

4. Akhlaghi, S., Hedenqvist, M. S., Conde Braña, M. T., Bellander, M., \& Gedde, U. W. (2015). Deterioration of acrylonitrile butadiene rubber in rapeseed biodiesel. Polymer Degradation \& Stability, 111(1), 211-222. http://dx.doi.org/10.1016/j. polymdegradstab.2014.11.012.

5. Mostafa, A., Abouel-Kasem, A., Bayoumi, M. R., \& El-Sebaie, M. G. (2009). The influence of CB loading on thermal aging resistance of SBR and NBR rubber compounds under different aging temperature. Materials \& Design, 30(3), 791-795. http:// dx.doi.org/10.1016/j.matdes.2008.05.065.

6. Trakarnpruk, W., \& Porntangjitlikit, S. (2008). Palm oil biodiesel synthesized with potassium loaded calcined hydrotalcite and effect of biodiesel blend on elastomer properties. Renewable Energy, 33(7), 1558-1563. http://dx.doi.org/10.1016/j. renene.2007.08.003.

7. Haseeb, A. S. M. A., Masjuki, H. H., Siang, C. T., \& Fazal, M. A. (2010). Compatibility of elastomers in palm biodiesel. Renewable Energy, 35(10), 2356-2361. http://dx.doi.org/10.1016/j. renene.2010.03.011.

8. Haseeb, A. S. M. A., Jun, T. S., Fazal, M. A., \& Masjuki, H. H. (2011). Degradation of physical properties of different elastomers upon exposure to palm biodiesel. Energy, 36(3), 1814-1819. http://dx.doi.org/10.1016/j.energy.2010.12.023.

9. Chai, A. B., Andriyana, A., Verron, E., \& Johan, M. R. (2013). Mechanical characteristics of swollen elastomers under cyclic loading. Materials \& Design, 44(x), 566-572. http://dx.doi. org/10.1016/j.matdes.2012.08.027.

10. Linhares, F. N., Corrêa, H. L., Khalil, C. N., Leite, M. C. A. M., \& Furtado, C. R. G. (2013). Study of the compatibility of nitrile rubber with Brazilian biodiesel. Energy, 49(1), 102-106. http://dx.doi.org/10.1016/j.energy.2012.10.040.

11. Chai, A. B., Andriyana, A., Verron, E., Johan, M. R., \& Haseeb, A. S. M. A. (2011). Development of a compression test device for investigating interaction between diffusion of biodiesel and large deformation in rubber. Polymer Testing, 30(8), 867-875. http://dx.doi.org/10.1016/j.polymertesting.2011.08.009.

12. Andriyana, A., Chai, A. B., Verron, E., \& Johan, M. R. (2012). Interaction between diffusion of palm biodiesel and large strain in rubber: effect on stress-softening during cyclic loading. Mechanics Research Communications, 43, 80-86. http://dx.doi. org/10.1016/j.mechrescom.2012.03.004.

13. Dubovský, M., Božek, M., \& Olšovský, M. (2015). Degradation of aviation sealing materials in rapeseed biodiesel. Journal of Applied Polymer Science, 132(28), 42254. http://dx.doi. org/10.1002/app.42254.

14. Akhlaghi, S., Pourrahimi, A. M., Hedenqvist, M. S., Sjöstedt, C., Bellander, M., \& Gedde, U. W. (2016). Degradation of carbon-black-filled acrylonitrile butadiene rubber in alternative fuels: Transesterified and hydrotreated vegetable oils. Polymer Degradation \& Stability, 123, 69-79. http://dx.doi.org/10.1016/j. polymdegradstab.2015.11.019.

15. Zhu, L., Cheung, C. S., Zhang, W. G., \& Huang, Z. (2015). Compatibility of different biodiesel composition with acrylonitrile butadiene rubber (NBR). Fuel, 158, 288-292. http://dx.doi. org/10.1016/j.fuel.2015.05.054.

16. Coronado, M., Montero, G., Valdez, B., Stoytcheva, M., Eliezer, A., García, C., Campbell, H., \& Pérez, A. (2014). Degradation of nitrile rubber fuel hose by biodiesel use. Energy, 68, 364369. http://dx.doi.org/10.1016/j.energy.2014.02.087. 
17. Akhlaghi, S., Gedde, U. W., Hedenqvist, M. S., Braña, M. T. C., \& Bellander, M. (2015). Deterioration of automotive rubbers in liquid biofuels: a review. Renewable \& Sustainable Energy Reviews, 43, 1238-1248. http://dx.doi.org/10.1016/j. rser.2014.11.096.

18. Giakoumis, E. G. (2013). A statistical investigation of biodiesel physical and chemical properties, and their correlation with the degree of unsaturation. Renewable Energy, 50, 858-878. http://dx.doi.org/10.1016/j.renene.2012.07.040.

19. Singh, S. P., \& Singh, D. (2010). Biodiesel production through the use of different sources and characterization of oils and their esters as the substitute of diesel: a review. Renewable \& Sustainable Energy Reviews, 14(1), 200-216. http://dx.doi. org/10.1016/j.rser.2009.07.017.

20. Oliveira, I. T. D., Pacheco, E. B. A. V., Visconte, L. L. Y., Oliveira, M. R. L., \& Rubinger, M. M. M. (2010). Efeito de um novo acelerador de vulcanização nas propriedades reométricas de composições de borracha nitrílica com diferentes teores de AN. Polímeros: Ciência e Tecnologia, 20(Especial), 366-370. http://dx.doi.org/10.1590/S0104-14282010005000059.

21. Flory, P. J. (1953). Principles of polymer chemistry. Ithaca: Cornell University.

22. Barlkanl, M., \& Hepburn, C. (1992). Determination of crosslink density by swelling in the castable polyurethane elastomer based on 1/4 - cyclohexane diisocyanate and para-phenylene diisocyante. Iranian Journal of Polymer Science \& Technology, 1(1), 1-5.

23. Forrest, M. J. (2001). Rubber analysis - polymers, compounds and products. Wolverhampton: Rapra Technology Ltd.

24. Ibarra, L., Rodríguez, A., \& Mora-Barrantes, I. (2008). Crosslinking of unfilled carboxylated nitrile rubber with different systems: influence on properties. Journal of Applied Polymer Science, 108(4), 2197-2205. http://dx.doi.org/10.1002/ app. 27893 .

25. Haseeb, A. S. M. A., Fazal, M. A., Jahirul, M. I., \& Masjuki, H. H. (2011). Compatibility of automotive materials in biodiesel: a review. Fuel, 90(3), 922-931. http://dx.doi.org/10.1016/j. fuel.2010.10.042.

26. Santos, E. M., Piovesan, N. D., Barros, E. G., \& Moreira, M. A. (2013). Low linolenic soybeans for biodiesel: characteristics, performance and advantages. Fuel, 104, 861-864. http://dx.doi. $\operatorname{org} / 10.1016 /$ j.fuel.2012.06.014.

Received: July 20, 2016

Revised: Nov. 24, 2016

Accepted: Jan. 17, 2017 